\title{
Convective Heat Transfer Coefficient for High Pressure Water Jet
}

\author{
Jong Wook $\mathrm{CHOI}$ and Jin Won $\mathrm{CHOI}^{11}$ \\ School of Mechanical and Automotive Engineering, Sunchon National University, Suncheon-City, 540-742, Korea. \\ 1) Technical Research Laboratories, Pohang Iron \& Steel Co., Ltd., Gwangyang-City, 545-090, Korea.
}

(Received on July 23, 2001; accepted in final form on December 5, 2001)

\begin{abstract}
The scale on the surface of hot rolled steel is removed by high pressure hydraulic descaling in a rolling mill. If the impact pressure of the water jet is higher, the scale is removed well. However, the temperature drop of the hot rolled steel is increased owing to the flow rate of the water jet. On this account, the temperature distribution of the hot rolled steel should be analyzed during the process of the hydraulic descaling. However, the analysis of the temperature distribution is difficult due to lack of the literatures on the convective heat transfer coefficient for the high pressure water jet. In the present study, the hydraulic descaling system is manufactured and the impact pressure is deduced from the relationship between spray pressure and spray height. And then the equation of the convective heat transfer coefficient is induced by the function of the impact pressure. The convective heat transfer coefficient is obtained from the experimental values by the hydraulic descaling system and the values calculated by numerical analysis. The equation of the convective heat transfer coefficient will aid to establish the most suitable conditions for operations in the rolling mill.
\end{abstract}

KEY WORDS: convective heat transfer coefficient; high pressure water jet; hydraulic descaling; impact pressure; temperature distribution.

\section{Introduction}

The scale is formed on the surface of hot rolled steel by its oxidation in a reheating furnace and is removed by the high pressure hydraulic descaling in the rolling mill. The machine of hydraulic descaling is called FSB (Finishing Scale Breaker), and is established in the front of FM (Finishing Mill). If the scale is not removed well, the rolled steel product has a defect caused by embedded scale behind the process of the FM. On this reason, the FSB plays an important part in the rolling mill. ${ }^{1)}$

Various mechanisms for the process by which the water jet removes the scale have been postulated. These mechanisms are divided into five ones which are steel-scale temperature difference, thermal gradient within scale, mechanical pressure, shear at interface, and explosive creation of steam within cracks. ${ }^{2)}$ And the combined mechanisms remove the scale, which operate at the same time.

As the temperature of the water jet and the hot rolled steel is fixed in a manufacturing process, the mechanisms related to the temperature don't leave much room for improvement. However, the mechanical pressure, that is, the impact pressure is open to further discussion. ${ }^{3)}$

Though the scale is removed well when the impact pressure is increased, the temperature drop of the hot rolled steel is increased owing to increasing the flow rate. As the hot rolled steel should be kept at over $\mathrm{A}_{3}$ transition temperature for the hot rolling, we could not increase the impact pressure extremely. On this account, the analysis of temperature distribution is needed for the hot rolled steel with the impact pressure during the process of the hydraulic descal- ing.

The convective heat transfer coefficient is necessary to the analysis of temperature distribution. As the convective heat transfer coefficient varies with the velocity of the fluid, the type of flow, the geometry of the body, flow passage area, the physical properties of the fluid, and so on, there is a few literatures related to it. ${ }^{4)}$

One of the literatures presents the equation of the convective heat transfer coefficient. ${ }^{5)}$ In this case, the equation satisfies at below $1 \mathrm{MPa}$, namely, at the low pressure. Another paper shows the value of the convective heat transfer coefficient at the high pressure. $\left.{ }^{6}\right)$ The value is approximately $209300 \mathrm{~W} / \mathrm{m}^{2}{ }^{\circ} \mathrm{C}$. However this equation and this value related to the convective heat transfer coefficient cannot apply to the analysis of temperature distribution during the process of the hydraulic descaling because we need the convective heat transfer coefficient with the various conditions.

In the present study, the hydraulic descaling system is manufactured for obtaining the impact pressure and the temperature variation of the hot rolled steel during the process of the hydraulic descaling. The impact pressure is deduced from the relationship between the spray pressure and the spray height.

The equation of the convective heat transfer coefficient is induced by the function of the impact pressure. The convective heat transfer coefficient is obtained from the experimental values by the hydraulic descaling system and the values calculated by the numerical analysis. The temperature distribution in the hot rolled steel is calculated by the FDM (Finite Difference Method). 


\section{The Hydraulic Descaling System}

The hydraulic descaling system is manufactured as shown in Fig. 1. The hydraulic descaling system consists of six parts, namely, the reheating furnace, the water tank, the plunger pump, the computer with $\mathrm{A} / \mathrm{D}$ board, the control panel, and the descaling simulator.

The specimen (hot rolled steel) is reheated at the reheating furnace. This furnace can hold up to $1400^{\circ} \mathrm{C}$. The scale is formed on the surface of specimen by its oxidation in the reheating furnace. The water tank and the plunger pump have a capacity of $2000 \mathrm{l}$ and $300 \mathrm{bar} \times 190 \mathrm{l} / \mathrm{min}$ respectively. Two plunger pumps supply the descaling simulator with water. The control panel regulates the supply of water, the velocity of a carriage, the spray height, and so on. The computer with the A/D board $(200 \mathrm{~Hz}, 16$ bit resolution) converts analogue signals to digital ones of the impact pressure and the temperature respectively, and displays the data in the monitor. The descaling simulator is the main part of the hydraulic descaling system as shown in Fig. 2.

The carriage (1) loaded with the specimen (2) moves from side to side. As the specimen is hot during the experiment, the carriage is made of ceramic in a contact surface with the specimen. When the impact pressure is measured, the sensor of the impact pressure instead of the specimen is laid on the carriage. The step motor (3) transfers power to the carriage using the urethane belt and controls the velocity of the carriage. The maximum velocity of the carriage is $200 \mathrm{mpm}$ (meter per min) and the maximum distance from side to side is $3.5 \mathrm{~m}$. The dimensions of the specimen are maximum $210 \mathrm{~mm}$ (Width) $\times 300 \mathrm{~mm}$ (Length) $\times 100 \mathrm{~mm}$ (Thickness).

The high pressure water is supplied to the nozzle header (4). And the nozzle header is controlled by the air cylinder (5) and the rotational angle of it is up to $45^{\circ}$ from side to side respectively. In the rolling mill, the lead angle of $15^{\circ}$ is set in order to prevent the scale from entering in the rolling

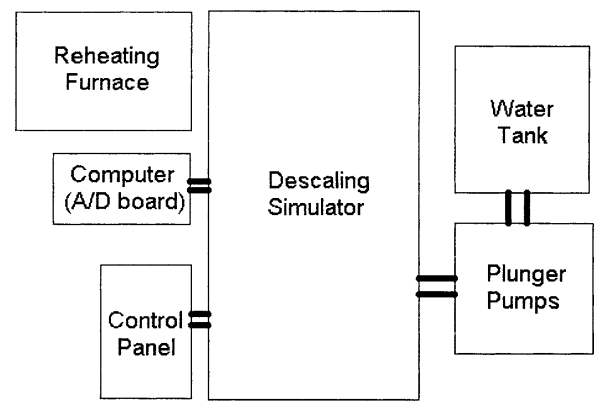

Fig. 1. The schematic diagram of the hydraulic descaling system.

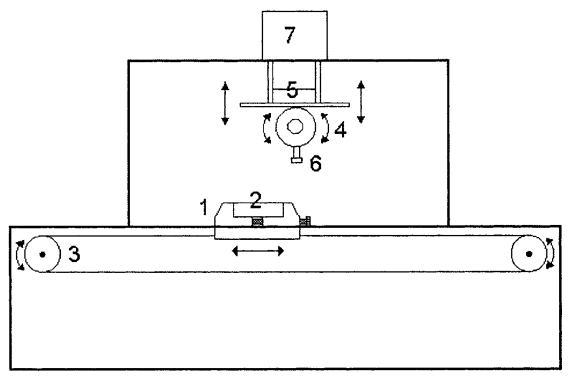

Fig. 2. The schematic diagram of the descaling simulator. machine. The descaling simulator can also experiment on this condition. The spray height, the distance between the nozzle (6) and the specimen, is controlled by another air cylinder (7).

\section{The Experiment on the Impact Pressure}

For measuring the impact pressure with the spray height and the spray pressure, the sensor of the impact pressure is laid on the carriage as shown in Fig. 3. The sensor of the impact pressure is the type of load cell and the area of sensing the impact force is $0.5 \mathrm{~cm}^{2}$. The moving velocity of the sensor is $5 \mathrm{~mm} / \mathrm{s}$, the cycle for data acquisition is $10 \mathrm{~Hz}$. That is, the data of impact force is obtained from the A/D converter at $0.5 \mathrm{~mm}$ intervals in the direction of width, and the impact force divided by the area of sensor gives the impact pressure. This impact pressure is obtained on the assumption that the impact force of the high pressure water acts on the sensor in an equal distribution and the effective impact force also acts on the area of sensor as a whole. In the present experiment, the distributions of the impact pressure are measured at 160,180, 200, 250, and 300 bar in the spray pressure respectively when the spray heights are 100 , $120,140,160$, and $180 \mathrm{~mm}$ respectively. That is, the number of experimental conditions is 25 .

\section{The Experiment on the Temperature Measurement}

For measuring the temperature variation in the specimen with time, the specimen set with a thermocouple is heated

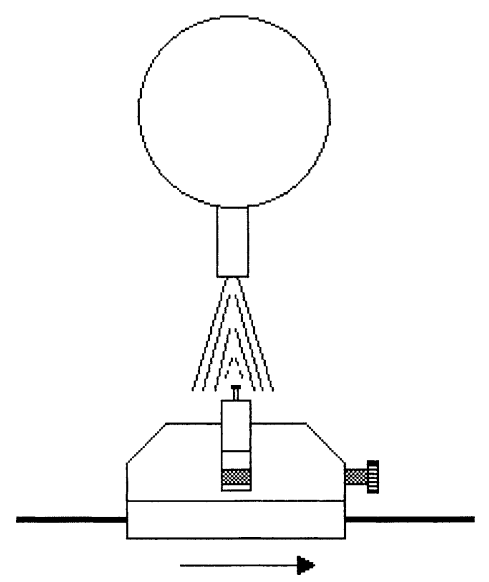

Fig. 3. The schematic diagram of measuring instrument for the impact pressure.

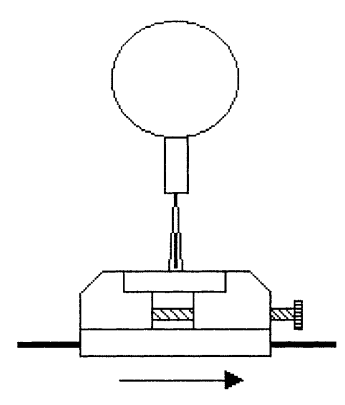

(a)

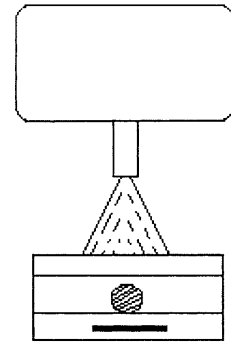

(b)
Fig. 4. The schematic diagram of measuring instrument for the temperature variation. 
in the reheating furnace of $1200^{\circ} \mathrm{C}$ for $1 \mathrm{~h}$ or so. And then, the specimen is laid on the carriage as shown in Fig. 4. Figures 4(a) and 4(b) represent a front view and an end view respectively.

The temperature variation is measured for the moving specimen at the velocity of $60 \mathrm{mpm}$. The position of thermocouple is the center of spray width and $3 \mathrm{~mm}$ in depth from the top surface of the specimen. The dimensions of the specimen used in the experiment are $150 \mathrm{~mm}$ (Width) $\times$ $200 \mathrm{~mm}$ (Length) $\times 25 \mathrm{~mm}$ (Thickness). Definitions of the width and the length of specimen are represented in Figs. 4(a) and 4(b) respectively.

\section{The Numerical Analysis}

The temperature distribution of the specimen through the high pressure water jet is analyzed assuming that the temperature variation in the direction of width is ignored and the effect of the scale is also disregarded. That is, the temperature distribution of the specimen is analyzed at the two dimensional section of the specimen. Two dimensional, time dependent heat conduction equation is expressed by Eq. (1).

$$
\frac{\partial T}{\partial t}=\alpha\left[\frac{\partial^{2} T}{\partial x^{2}}+\frac{\partial^{2} T}{\partial y^{2}}\right]
$$

Where $T$ is the temperature $\left({ }^{\circ} \mathrm{C}\right), t$ is the time $(\mathrm{s}), \alpha$ $(=k / \rho c)$ and is the thermal diffusivity $\left(\mathrm{m}^{2} / \mathrm{s}\right)$. The thermal conductivity $(k)$, the density $(\rho)$ and the specific heat $(c)$ of the strip are $50 \mathrm{~W} / \mathrm{m}^{\circ} \mathrm{C}, 7870 \mathrm{~kg} / \mathrm{m}^{3}$, and $875 \mathrm{~J} / \mathrm{kg}{ }^{\circ} \mathrm{C}$, respectively. So, the thermal diffusivity used in the calculation is $7.2608 \times 10^{-6} \mathrm{~m}^{2} / \mathrm{s}$.

From the Eq. (1), an explicit finite difference equation using forward differencing for the time derivative and central differencing for the space derivative is Eq. (2).

$$
\begin{aligned}
& \frac{T_{m, n}^{i+1}-T_{m, n}^{i}}{\Delta t} \\
& =\alpha\left[\frac{T_{m-1, n}^{i}-2 T_{m, n}^{i}+T_{m+1, n}^{i}}{(\Delta x)^{2}}+\frac{T_{m, n-1}^{i}-2 T_{m, n}^{i}+T_{m, n+1}^{i}}{(\Delta y)^{2}}\right]
\end{aligned}
$$

Where $i$ is the time level, $m$ is the grid point in the direction, $n$ is the grid point in the $y$ direction, $\Delta t$ is the time step, $\Delta x$ is the size of grid step in the $x$ direction and $\Delta y$ is the size of grid step in the $y$ direction.

The grids and the boundary conditions on the computational domain are shown in Fig. 5. The number of the grid elements is $5000(200 \times 25)$ and the grid step is $0.001 \mathrm{~m}$ in

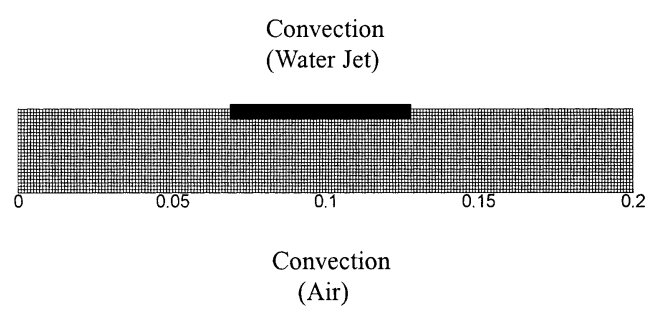

Fig. 5. The grids and the boundary conditions. size and time step is $0.002 \mathrm{~s}$. The values satisfy the Eq. (3) of the stability condition. ${ }^{7)}$

$$
\left[\frac{\alpha \Delta t}{(\Delta x)^{2}}+\frac{\alpha \Delta t}{(\Delta y)^{2}}\right] \leq \frac{1}{2}
$$

The following procedures and conditions are used in order to calculate the temperature distribution of the specimen.

(1) The Heat Transfer before the Hydraulic Descaling

The temperature data obtained from the experiment on the temperature measurement are utilized for calculating the temperature distribution of the specimen. The convective heat transfer coefficient is determined when the numerical results are in good agreement with the experimental ones. And the gradient of temperature depends on the convective heat transfer coefficient. At this process, the convection boundary condition is considered on account of the air only and the temperature of the air is $21.3^{\circ} \mathrm{C}$.

(2) The Heat Transfer during the Hydraulic Descaling

When the specimen is passing through the high pressure water jet, the numerical analysis of the heat transfer is accomplished with regard to the descaling time, the temperature drop, and so on. Where, the temperature of water is $20.1^{\circ} \mathrm{C}$ and the descaling time is calculated by the Eq. (4).

$$
t_{\mathrm{s}}=\frac{l_{\mathrm{s}}}{v_{\mathrm{m}}}
$$

Where $t_{\mathrm{s}}$ is the spraying time $(\mathrm{s}), l_{\mathrm{s}}$ is the spray thickness (m) and $v_{\mathrm{m}}$ is the velocity of moving specimen $(\mathrm{m} / \mathrm{s})$.

(3) The Heat Transfer after the Hydraulic Descaling

The convective heat transfer coefficient is determined with regard to a restoring tendency of the temperature after the hydraulic descaling. Where, the convection boundary condition is considered by the air and the residual water.

\section{The Results}

\subsection{The Results of the Experiment on the Impact Pressure}

The diameters of the spray nozzle (DNR type) used in the experiment are $3.4 \mathrm{~mm}$ in the minor axis and $4.5 \mathrm{~mm}$ in the major axis. And the spray angle and the flow rate are $28^{\circ}$ and $118 \mathrm{l} / \mathrm{min}$ at the $150 \mathrm{bar}$, respectively. The impact pressures are measured with respect to the spray width. When the spray pressure $(P)$ is 250 bar and the spray height $(H)$ is $140 \mathrm{~mm}$, the distribution of the impact pressure with the spray width is shown in Fig. 6. As we are interested in the variation of the impact pressure with the spray pressure and the spray height, the representative impact pressure in these conditions is regarded as one at the center of the spray width. As a result, the contour plot for the representative impact pressures using the experimental values is shown in Fig. 7.

As the spray pressure is increased and the spray height is decreased, the representative impact pressure is increased. The variations of the impact pressure are shown in Fig. 8 when the spray heights are $100,120,140,160$, and $180 \mathrm{~mm}$ 


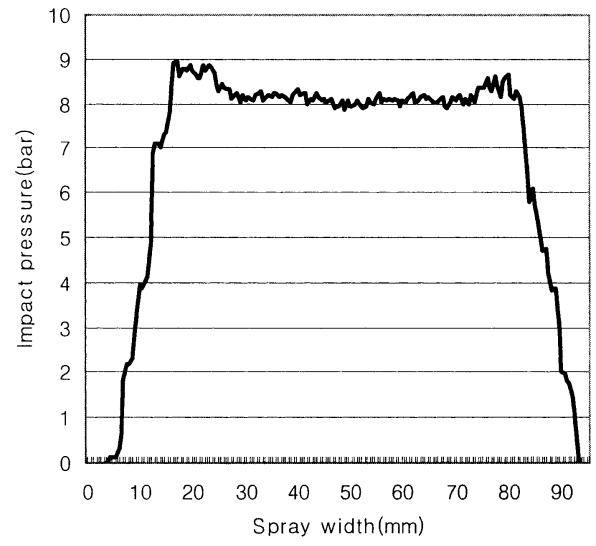

Fig. 6. The distribution of the impact pressure with the spray width $(P=250$ bar, $H=140 \mathrm{~mm})$.

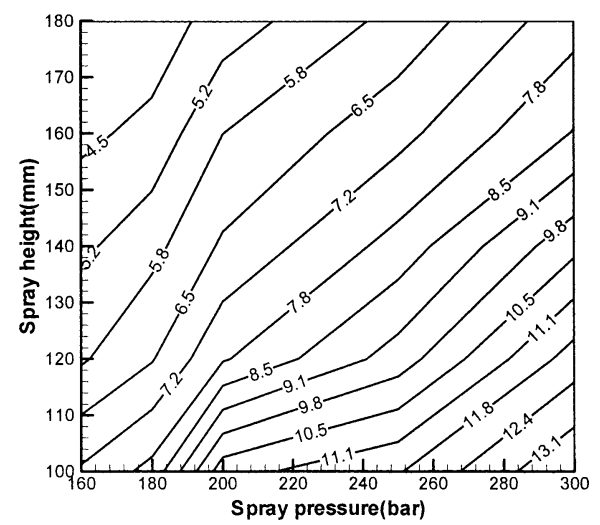

Fig. 7. The contour plot for the representative impact pressure (bar).

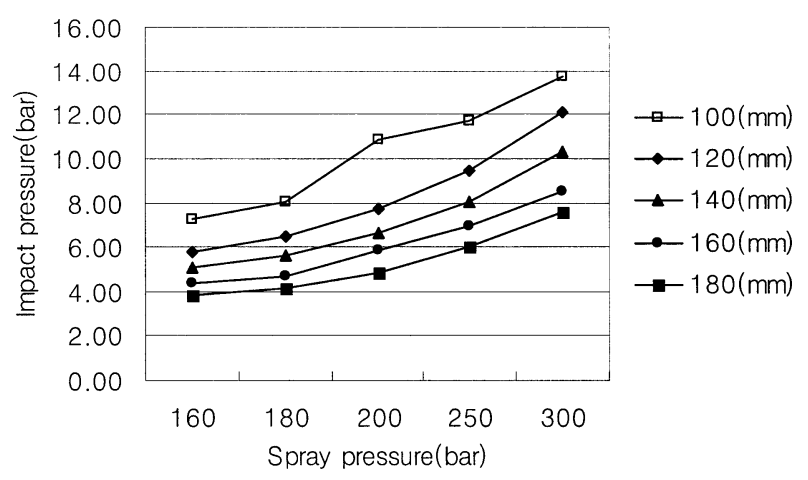

Fig. 8. The variations of the impact pressure with the spray pressure.

respectively. The equations of the impact pressure are obtained from the curved lines respectively in Fig. 8. If the program is made as the flow chart in Fig. 9 using the equations of the impact pressure, the impact pressure is obtained without difficulty in the extent of that the spray pressure is between 160 and 300 bar and the spray height is between 100 and $180 \mathrm{~mm}$. Where, as the linear interpolation method is used in the program, there is somewhat a numerical error. On the other hand, the impact pressure is calculated using the program instead of the general expression that has the independent variables of the spray pressure and the spray height. And then the equation of the convective heat transfer coefficient is obtained as the function of impact pres-

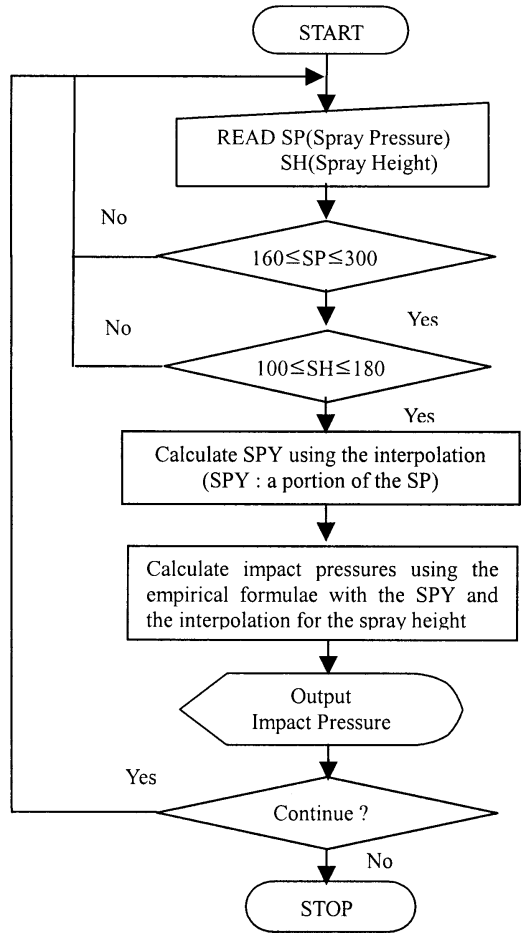

Fig. 9. The flow chart for calculating impact pressure.

sure. As the impact pressure depends on the spray pressure and the spray height, the equation of the convective heat transfer coefficient also depends on the spray pressure and the spray height.

If the different nozzle is selected for the descaling, there is no necessity for measuring the relation between the spray pressure and the impact pressure in Fig. 8 again. However, as the convective heat transfer coefficient is the function of impact pressure and the impact pressure also depends on nozzle type and nozzle maker, the impact pressure should be measured at the specific spray pressure and the specific spray height.

\subsection{The Comparison of the Experimental Results and the Numerical Ones for the Temperature}

The convective heat transfer coefficient is obtained from the comparison of the experimental results and the numerical ones for the temperature variation as shown in Figs. 10-16. These figures represent the results of temperature variation when the impact pressures are 4.82, 5.04, 5.75, $5.83,6.94,7.25$, and 8.07 bar, respectively. On the other hand, the impact pressures were measured in the 25 cases with the spray pressure and the spray height. However, as the convective heat transfer coefficient is the function of only the impact pressure in the present study, we experimented for the 7 cases among the 25 cases with the impact pressure in the experiment on the temperature measurement.

Here, the values of spray thickness are obtained from the spray pattern observed on the lead plate. The high pressure water jet is sprayed on the lead plate for $1 \mathrm{~min}$ with respect to the conditions of impact pressure. As a result of the test, the values of spray thickness are approximately $6-8 \mathrm{~mm}$ and the variations of these values are a little unlike the spray width with respect to the spray height and the spray pressure. The spraying time can be obtained from these re- 


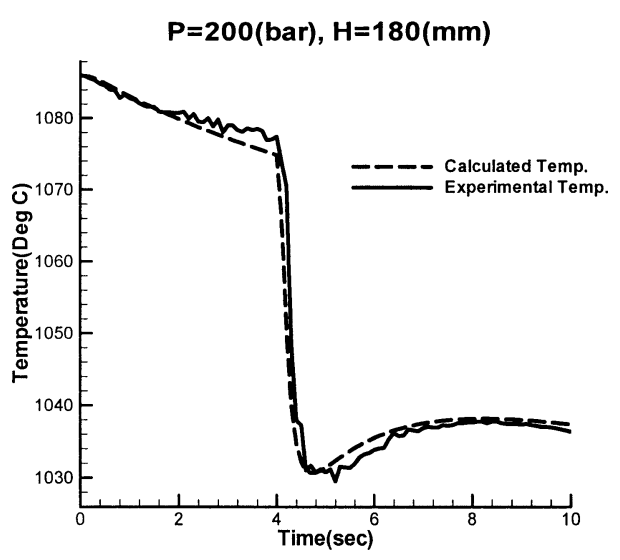

Fig. 10. The temperature variation at $I P=4.82$ (bar).

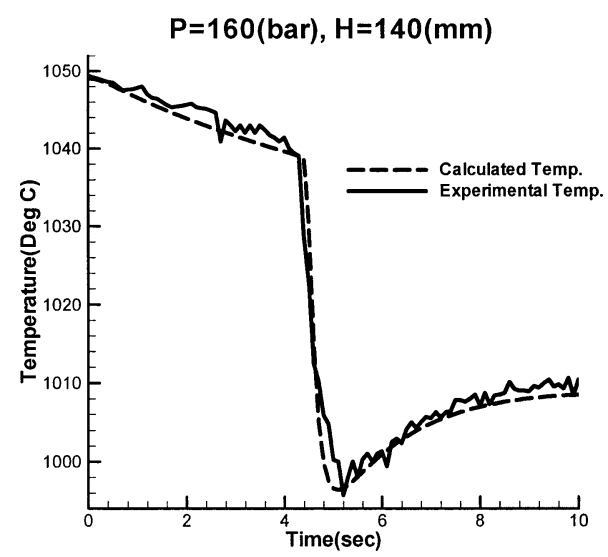

Fig. 11. The temperature variation at $I P=5.04$ (bar).

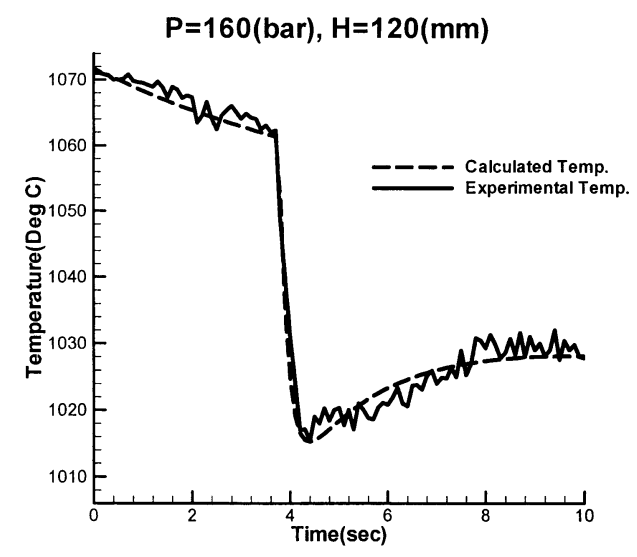

Fig. 12. The temperature variation at $I P=5.75$ (bar).

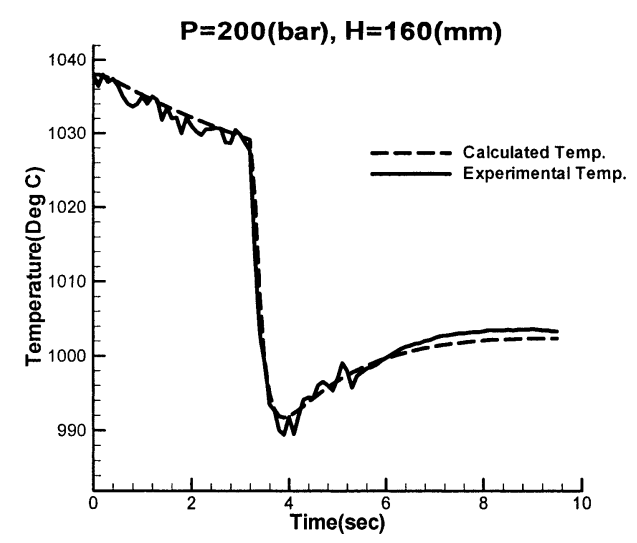

Fig. 13. The temperature variation at $I P=5.83$ (bar).

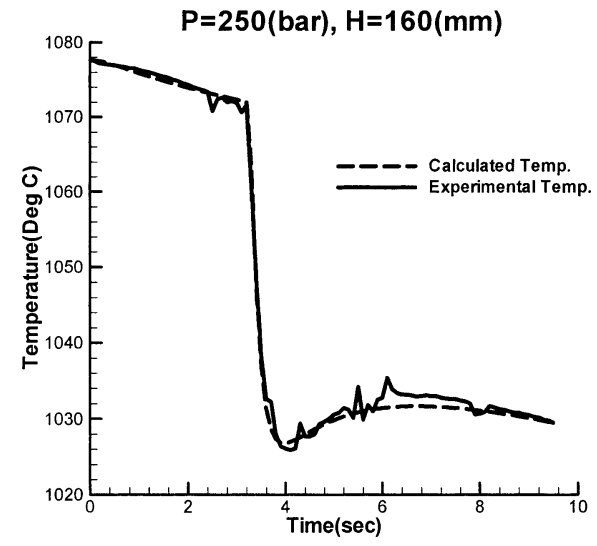

Fig. 14. The temperature variation at $I P=6.94$ (bar).

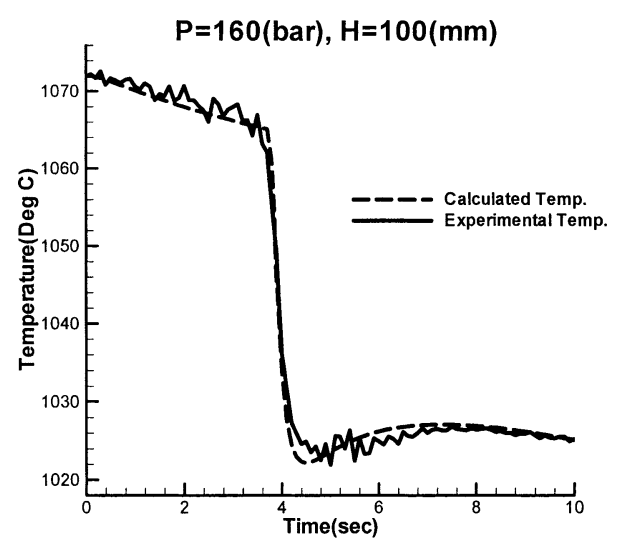

Fig. 15. The temperature variation at $I P=7.25$ (bar).

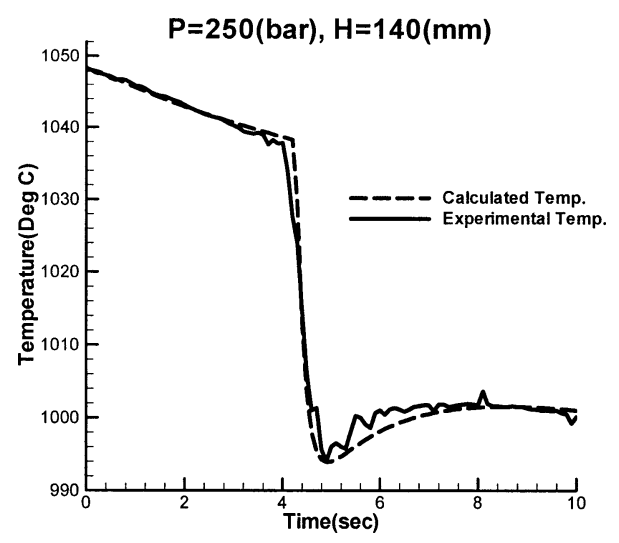

Fig. 16. The temperature variation at $I P=8.07$ (bar).

sults and then the temperature distributions are calculated for obtaining the convective heat transfer coefficients. And the convective heat transfer coefficients are determined in consideration for the temperature gradients and its track with time.

As the hot specimen on the carriage is moved without the effect of the water before the hydraulic descaling, the convection boundary conditions are considered by the air only. The effect of the high pressure water jet is considered during the hydraulic descaling. The residual water affects the temperature variation of the specimen after the hydraulic descaling. Therefore the gradient of temperature after the hydraulic descaling is steeper than that of temperature before the hydraulic descaling. In the water jet cooling by the 


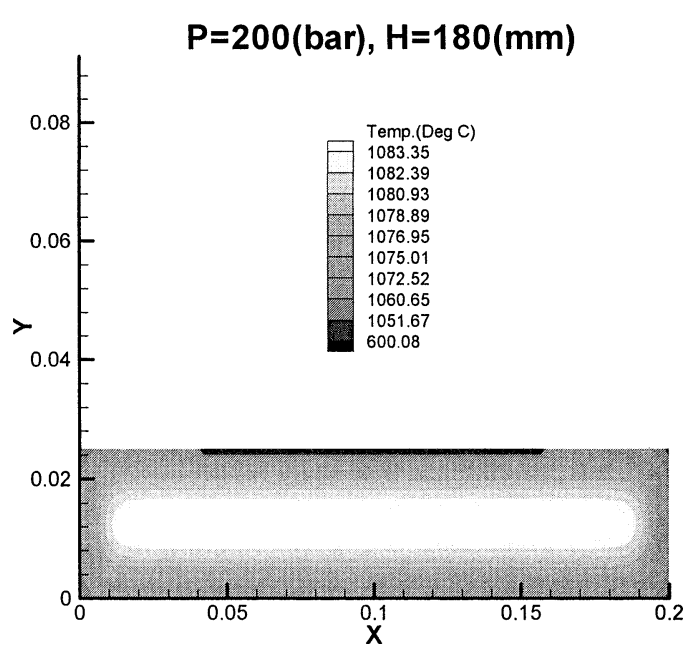

Fig. 17. The temperature distribution at $t=4.008$ (s).

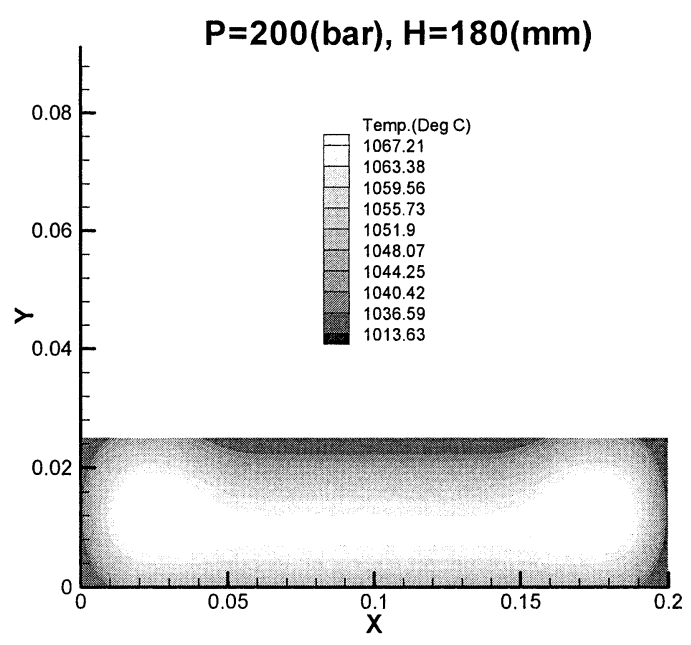

Fig. 18. The temperature distribution at $t=10.308$ (s).

high pressure, the convective heat transfer coefficient is greatly influenced by the velocity of the fluid. So, the convective heat transfer coefficient can be regarded as a step function because the velocity of the fluid in the water jet cooling zone is very higher than that in the area outside the water jet cooling zone.

The temperature distribution at the section of the specimen immediately after the hydraulic descaling is shown in Fig. 17. The hydraulic descaling starts at $t=4 \mathrm{~s}$ and ends at $t=4.008 \mathrm{~s}$, that is, the time required during the hydraulic descaling is $0.008 \mathrm{~s}$. The temperature at the top and center of the specimen falls up to $600^{\circ} \mathrm{C}$. Figure 18 shows the temperature distribution at $6.3 \mathrm{~s}$ after the hydraulic descaling is finished. That means the time required between the hydraulic descaling and the hot rolling in the rolling mill. The temperature at the top and center of the specimen is restored up to $1000^{\circ} \mathrm{C}$ and above. This temperature represents over $\mathrm{A}_{3}$ transition temperature for the hot rolling. The temperature at the edge parts of specimen is lower as compared with other parts because the area of the heat transfer is large at the edge parts.

\subsection{The Convective Heat Transfer Coefficient}

The convective heat transfer coefficients with the impact pressure are shown in Fig. 19. The convective heat transfer

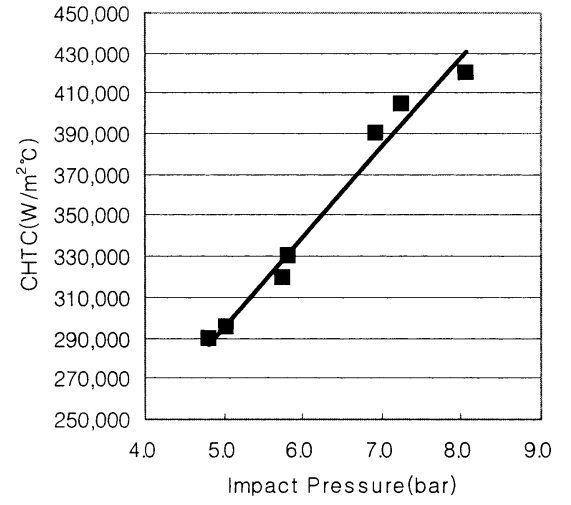

Fig. 19. The convective heat transfer coefficient with the impact pressure.

coefficient is increased as the impact pressure is increased. The impact pressure is increased as the spray pressure is increased and the spray height is decreased. If the impact pressure is increased, the flow rate is also increased, and the heat flux by the convection is also increased.

The convective heat transfer coefficients for the high pressure water jet are between 290000 and 420000 $\mathrm{W} / \mathrm{m}^{2}{ }^{\circ} \mathrm{C}$ when the impact pressures are between 4.82 and 8.07 bar. The general expression of the convective heat transfer coefficient is Eq. (5).

$$
h=(4.4265 \times I P+7.3670) \times 10^{4}
$$

Where $h$ is the convective heat transfer coefficient $\left(\mathrm{W} / \mathrm{m}^{2}{ }^{\circ} \mathrm{C}\right)$ and $I P$ is the impact pressure (bar). On the other hand, the convective heat transfer coefficients are between 90 and $150 \mathrm{~W} / \mathrm{m}^{2}{ }^{\circ} \mathrm{C}$ by the air and between 120 and $250 \mathrm{~W} / \mathrm{m}^{2}{ }^{\circ} \mathrm{C}$ by the residual water and the air.

\section{Conclusion}

The scale is formed on the surface of the hot rolled steel by its oxidation in the reheating furnace and is removed by the high pressure water jet. If the impact pressure of the water jet is increased so as to remove the scale well, the temperature drop of the hot rolled steel may be increased due to increasing the flow rate. However, the hot rolled steel should be kept at over $\mathrm{A}_{3}$ transition temperature. And so, the analysis of the temperature distribution for the hot rolled steel is required in order to satisfy these conditions. The convective heat transfer coefficient is also needed for the analysis of the temperature distribution. The convective heat transfer coefficient can be obtained from the results of the experiment and the numerical analysis.

Therefore the hydraulic descaling system was manufactured in the present study. The program was made for the purpose of obtaining the impact pressure with the spray pressure and the spray height. The general expression of the convective heat transfer coefficient was obtained in relation to the impact pressure.

If the programs of the impact pressure are made for other nozzles, the convective heat transfer coefficient can be obtained without additional experiments on the temperature measurement. Therefore the cost and the time of the experiment can be saved. And the general equation of the convective heat transfer coefficient may be used in the analysis of 
the temperature distribution connected with nozzle. In addition, this equation will aid to establish the most suitable conditions for operations in the rolling mill. In the present study, we have not considered the effect of the scale, the variations of the impact pressure in the direction of width and the heat transfer in the three dimensional geometry. We leave these topics for further study.

\section{Acknowledgements}

The work was supported by the Brain Korea 21 Project and Technical Research Laboratories in POSCO. The authors would like to thank for these supports.

\section{REFERENCES}

1) T. K. Kurita, Y. Kudo and S. Odagiri: Proc. of 1st Int. Conf. on Hydraulic Descaling in Rolling Mills, Painters Hall, London, (1995).

2) H. F. Marston: Proc. of 1st Int. Conf. on Hydraulic Descaling in Rolling Mills, Painters Hall, London, (1995).

3) J. Gaydoul: Proc. of 1st Int. Conf. on Hydraulic Descaling in Rolling Mills, Painters Hall, London, (1995).

4) M. N. Özişik: Heat Transfer, McGraw-Hill, New York, (1985), 6.

5) T. Wada, M. Oshimi and M. Ueda: Tetsu-to-Hagané, 77 (1991), 1464.

6) H. Müller and R. Jeschar: Arch. Eisenhüttenwes., 44 (1973), 589.

7) K. A. Hoffmann and S. T. Chiang: Computational Fluid Dynamics for Engineers, Engineering Education System, Wichita, Kansas, (1993), 78 